\title{
Synaptic Distributions of GluA2 and PKM $\zeta$ in the Monkey Dentate Gyrus and Their Relationships with Aging and Memory
}

\author{
Yuko Hara, ${ }^{1,2}$ Michael Punsoni, ${ }^{1,2}$ Frank Yuk, ${ }^{1,2}$ C. Sehwan Park, ${ }^{1,2}$ William G. M. Janssen, ${ }^{1,2}$ Peter R. Rapp, ${ }^{5}$ \\ and John H. Morrison ${ }^{1,2,3,4}$ \\ ${ }^{1}$ Fishberg Department of Neuroscience and Kastor Neurobiology of Aging Laboratories, ${ }^{2}$ Friedman Brain Institute, ${ }^{3}$ Department of Geriatrics and Palliative \\ Medicine, and ${ }^{4}$ Computational Neurobiology and Imaging Center, Mount Sinai School of Medicine, New York, New York 10029, and ${ }^{5}$ National Institute on \\ Aging, Laboratory of Experimental Gerontology, Baltimore, Maryland 21224
}

\begin{abstract}
Rhesus monkeys provide a valuable model for studying the neurobiological basis of cognitive aging, because they are vulnerable to age-related memory decline in a manner similar to humans. In this study, young and aged monkeys were first tested on a well characterized recognition memory test (delayed nonmatching-to-sample; DNMS). Then, electron microscopic immunocytochemistry was performed to determine the subcellular localization of two proteins in the hippocampal dentate gyrus (DG): the GluA2 subunit of the glutamate AMPA receptor and the atypical protein kinase $\mathrm{C} \zeta$ isoform $(\mathrm{PKM} \zeta)$. $\mathrm{PKM} \zeta$ promotes memory storage by regulating GluA2containing AMPA receptor trafficking. Thus, we examined whether the distribution of GluA2 and PKM $\zeta$ is altered with aging in DG axospinous synapses and whether it is coupled with memory deficits. Monkeys with faster DNMS task acquisition and more accurate recognition memory exhibited higher proportions of dendritic spines coexpressing GluA2 and PKM $\zeta$. These double-labeled spines had larger synapses, as measured by postsynaptic density area, than single-labeled and unlabeled spines. Within this population of doublelabeled spines, aged monkeys compared with young expressed a lower density of synaptic GluA2 immunogold labeling, which correlated with lower recognition accuracy. Additionally, higher density of synaptic PKM $\zeta$ labeling in double-labeled spines correlated with both faster task acquisition and better retention. Together, these findings suggest that age-related impairment in maintenance of GluA2 at the synapse in the primate hippocampus is coupled with memory deficits.
\end{abstract}

\section{Introduction}

Memory loss due to advanced age or Alzheimer's disease has been attributed, in part, to alterations in the perforant path projection from the entorhinal cortex to the dentate gyrus (DG) of the hippocampus (Flood et al., 1987; Cabalka et al., 1992; Small et al., 2004; Yassa et al., 2010). Rhesus monkeys provide a valuable model for studying the neurobiological basis of cognitive aging, because their cognitive status can be assessed using a well characterized battery of neuropsychological tests, including the delayed nonmatching-to-sample (DNMS) test of recognition memory

\footnotetext{
Received Feb. 8, 2012; revised March 30, 2012; accepted April 3, 2012

Author contributions:Y.H., P.R.R., and J.H.M. designed research;Y.H., M.P., F.Y., C.S.P., and W.G.M.J. performed research; Y.H. analyzed data; Y.H., P.R.R., and J.H.M. wrote the paper.

This work was supported by National Institute on Aging Grants R37 AG06647 and R01 AG010606 to J.H.M., and in part by the Intramural Research Program of the National Institute on Aging. We thank Mary Roberts, Sania Fong, Deborah Kent, Katie Hartley, Sona Santos, Heather McKay, and Anne Canfield at the California National Primate Research Center for their expert technical assistance involving the rhesus monkeys, and Dr. Donald Canfield for assistance in veterinary work. We also thank Susan Fink, Ginelle Andrews, Shannon Wadsworth, and Rishi Puri for expert technical assistance in tissue processing.

The monoclonal antibody to glutamate receptor GluA2 subunit used in this study was developed by J.H.M. and collaborators and is commercially available through licensing arrangements between Mount Sinai School of Medicine and various companies.

Correspondence should be addressed to Dr. John H. Morrison, Department of Neuroscience, Box 1065, Mount Sinai School of Medicine, One Gustave L. Levy Place, New York, NY 10029. E-mail: john.morrison@mssm.edu.

DOI:10.1523/JNEUROSCI.0605-12.2012

Copyright $\odot 2012$ the authors $\quad 0270-6474 / 12 / 327336-09 \$ 15.00 / 0$
}

(Presty et al., 1987; Moss et al., 1988; Rapp and Amaral, 1991). In these same monkeys, structural and molecular profiles can be examined to explore which measures are altered with aging, and specifically in association with cognitive decline.

While DG volume, granule cell number, overall synapse density, and synapse size remain stable in aged monkeys (Keuker et al., 2003; Calhoun et al., 2004; Shamy et al., 2006; Hara et al., 2012), we have previously highlighted the significance of perforated synapses for normal memory (Hara et al., 2012), and reported age-related increases in nonsynaptic boutons which were coupled with recognition memory deficits (Hara et al., 2011a). However, the molecular makeup of DG synapses has received little attention in the context of normal aging and memory decline in this nonhuman primate model.

Glutamate AMPA receptors are highly mobile proteins that undergo dynamic trafficking into and out of the synapse in a tightly regulated and activity-dependent manner (Groc and Choquet, 2006; Kessels and Malinow, 2009). The number, synaptic location, and subunit composition of AMPA receptors potently regulate synaptic plasticity and strength (Henley et al., 2011). GluA2 is the most abundant subunit of AMPA receptors in the adult brain and plays a critical role in synaptic plasticity and memory (Mead and Stephens, 2003; Migues et al., 2010).

Protein kinase $\mathrm{M} \zeta(\mathrm{PKM} \zeta)$ is a $\mathrm{PKC}$ isoform that contains a $\zeta$ catalytic domain without the $\mathrm{N}$-terminal regulatory domain, ren- 
dering it constitutively active (Sacktor et al., 1993, 2011). It is expressed exclusively in the brain and is enriched in the hippocampus and neocortex (Hernandez et al., 2003; Oster et al., 2004; Crary et al., 2006). PKM $\zeta$ plays a role in maintenance of hippocampus-dependent memory (Hernandez et al., 2003; Pastalkova et al., 2006; Serrano et al., 2008; Hardt et al., 2010) and exerts its functions by blocking a GluA2-dependent pathway for removal of AMPA receptors from the postsynaptic site, thus promoting persistent GluA2 expression at the synapse (Migues et al., 2010). In contrast to many short-acting molecules involved in memory formation, $\mathrm{PKM} \zeta$ is unique in that its persistent activity is critical for storage of memory, long after its formation (Shema et al., 2009; Sacktor, 2011).

The present study tested the hypothesis that age-related recognition memory impairment in rhesus monkeys is coupled with changes in the subcellular distribution of GluA2 and/or PKM $\zeta$ in DG axospinous synapses. We discovered an age-related decrease in synaptic GluA2 in dendritic spines coexpressing PKM $\zeta$, which correlated with recognition memory deficits.

\section{Materials and Methods}

Animals. Subjects comprised five young adult (mean \pm SEM; $9.72 \pm 0.20$ years old) and 12 aged (mean \pm SEM; $29.52 \pm 1.26$ years old) female rhesus monkeys (Macaca mulatta). The maximal lifespan of a rhesus monkey is 35-40 years of age, and the average life span of captive rhesus monkeys is $<25$ years (Tigges et al., 1988). Although human age equivalence can be approximately estimated at 1:3, menopause in rhesus monkeys occurs by 27 years old, which is later in life relative to humans (Gilardi et al., 1997; Walker and Herndon, 2008). Monkeys were housed at the California National Primate Research Center, University of California, Davis in colonies of $\sim 40$ individuals. None of the subjects received prior invasive or pharmacological manipulations expected to influence the cognitive or neurobiological measures examined here. Menses status was determined as described previously (Hara et al., 2011a, 2012) and was confirmed by urine endocrine analysis for 12 of 17 monkeys. All experiments were conducted in compliance with the National Institutes of Health Guidelines for the Care and Use of Experimental Animals and approved by the Institutional Animal Care and Use Committee at the University of California, Davis.

DNMS test. DNMS, a well characterized visual recognition memory test, was conducted in a manual apparatus as described previously (Rapp and Amaral, 1991; Rapp et al., 2003). Briefly, a monkey was presented with a sample object covering a food reward in the central well of the test tray. After the subject retrieved the reward, the delay period started during which an opaque barrier was lowered. After the delay interval, the sample item was presented together with a novel object, and the subject was rewarded for choosing the novel object. Throughout the trials, the experimenter was hidden from view behind a one-way mirror, and a white-noise generator masked extraneous sounds. During the acquisition phase, the retention interval was set at $10 \mathrm{~s}$ until monkeys learned the nonmatching rule of the task. Once monkeys reached a criterion of $90 \%$ correct or better at this delay interval (across 100 trials, 20 trials/d), recognition memory was challenged by imposing successively longer delay intervals of 15, 30, 60, $120 \mathrm{~s}$ (100 trials total at each delay, 20 trials/d), and $600 \mathrm{~s}$ (50 trials total, 5 trials/d) during which monkeys remained in the test chamber. Intertrial interval was $30 \mathrm{~s}$ throughout testing.

When perfusion could not be scheduled immediately after completion of behavioral testing, monkeys continued mock testing until the day before perfusion. There were no significant differences by age or menses status in the amount of time lapsed between the last day of DNMS testing and the perfusion date $(p>0.05)$.

Perfusion and tissue processing for electron microscopy. Monkeys were deeply anesthetized with ketamine hydrochloride $(25 \mathrm{mg} / \mathrm{kg})$ and pentobarbital (20-35 mg/kg, i.v.), intubated, and mechanically ventilated. After $1.5 \mathrm{ml}$ of $0.5 \%$ sodium nitrate was injected into the left ventricle of the heart, the descending aorta was clamped. Monkeys were perfused transcardially with cold $1 \%$ paraformaldehyde in $0.1 \mathrm{~m}$ phosphate buffer
(PB; pH 7.2) for $2 \mathrm{~min}$, followed by $4 \%$ paraformaldehyde in $0.1 \mathrm{M} \mathrm{PB}$ at $250 \mathrm{ml} / \mathrm{min}$ for $10 \mathrm{~min}$. The flow rate was then reduced to $100 \mathrm{ml} / \mathrm{min}$ for $50 \mathrm{~min}$. Following perfusion, the brain was dissected to include the entire right hippocampal region in a single block. The hippocampal block was postfixed for $6 \mathrm{~h}$ in $4 \%$ paraformaldehyde and $0.125 \%$ glutaraldehyde in $0.1 \mathrm{M}$ PB, washed in $0.1 \mathrm{M} \mathrm{PB}$, and cut into $400-\mu \mathrm{m}$-thick sections on a vibratome (Leica). Freeze substitution and low-temperature embedding of the specimens were performed as described previously (Chaudhry et al., 1995). Briefly, sections were cryoprotected by immersion in increasing concentrations of glycerol in $0.1 \mathrm{M} \mathrm{PB}$, and then plunged in liquid propane cooled by liquid nitrogen in a Universal Cryofixation System KF80 (Reichert-Jung). Sections were then immersed in 1.5\% uranyl acetate in anhydrous methanol $\left(-90^{\circ} \mathrm{C}\right)$ for $24 \mathrm{~h}$ in a cryosubstitution Automatic Freeze-Substitution System unit (Leica). The temperature was raised $4^{\circ} \mathrm{C} / \mathrm{h}$ from -90 to $-45^{\circ} \mathrm{C}$. The sections were washed with anhydrous methanol and infiltrated with increasing concentrations of Lowicryl HM20 resin (Electron Microscopy Sciences) for $1 \mathrm{~h}$ each, followed by $100 \%$ Lowicryl overnight. The resin was polymerized by UV light $(360 \mathrm{~nm})$ at $-45^{\circ} \mathrm{C}$ for $48 \mathrm{~h}$, followed by $24 \mathrm{~h}$ at room temperature. Eight or more consecutive ultrathin sections were cut into 90-nm-thick sections using a Diatome diamond knife (Electron Microscopy Sciences) and mounted on each formvar-supported slot grid (Electron Microscopy Sciences).

Antibodies. A well characterized mouse monoclonal antibody (6C4) raised against a fusion protein corresponding to the $\mathrm{N}$-terminal portion (amino acids 175-430) of the AMPA receptor GluA2 subunit was used. This antibody has been extensively tested and shown to specifically recognize the GluA2 subunit by Western blot, radioimmunoassay, and immunocytochemistry on transfected cells (Vissavajjhala et al., 1996). Furthermore, 6C4 has been used previously for electron microscopic immunocytochemistry (Vissavajjhala et al., 1996; He et al., 2000, 2001).

A rabbit polyclonal antiserum raised against a synthetic phosphopeptide $(<20 \mathrm{aa})$ corresponding to residues surrounding Thr 410 of human PKC $\zeta$ was obtained commercially (sc-12894R; Santa Cruz Biotechnology). This antiserum also recognizes phosphorylated $\mathrm{PKC} \iota$, the other atypical PKC that shares a nearly identical $\mathrm{C}$ terminus with $\mathrm{PKC} \zeta$ (Hernandez et al., 2003). PKCı, however, localizes to the cell body and nucleus (White et al., 2002) and is involved in organization of the Golgi apparatus (Tanabe et al., 2010) and microtubules (Tisdale, 2002), both of which are absent in the dendritic spine. Although PKM $\zeta$ immunolabeling is indistinguishable from $\mathrm{PKC} \zeta$ immunolabeling due to their identi$\mathrm{cal}$ amino acid sequence, $\mathrm{PKM} \zeta$ is expressed in the forebrain as the major form of $\zeta$ in the near absence of PKC $\zeta$ in rodents (Hernandez et al., 2003; Oster et al., 2004) and in humans (Crary et al., 2006). Thus immunoreactivity of this antiserum in the hippocampus of rhesus monkeys is assumed to predominantly represent the presence of PKM $\zeta$. An antibody recognizing the phospho-protein was chosen, because phosphorylation at the Thr 410 residue reflects high constitutive kinase activity of PKM $\zeta$ (Kelly et al., 2007; Sacktor, 2011). Western blotting of 293T cells transfected with human PKC $\zeta$ has shown that this antiserum recognizes a band corresponding to the molecular weight of $\mathrm{PKC} \zeta$, which disappears with application of lambda protein phosphatase. Specificity of this antiserum was further confirmed in a peptide adsorption control experiment in which no immunogold labeling was observed.

Postembedding immunogold labeling. The sections were first treated with $0.1 \%$ sodium borohydride and $50 \mathrm{~mm}$ glycine to remove excess aldehydes, rinsed thoroughly with $0.3 \%$ saline $/ 0.005 \mathrm{~m}$ Tris (TBS), and then incubated in TBS containing 6\% human serum albumin (HSA; Sigma RBI) and $0.01 \%$ Tergitol, type NP-10 (Sigma RBI) for 30 min to block nonspecific binding of antisera. The sections were incubated overnight in a primary antibody solution consisting of anti-GluA2 $(6 \mathrm{C} 4 ; 2$ $\mu \mathrm{g} / \mathrm{ml}$ ), anti-PKC/M $\zeta(\mathrm{sc}-12894 \mathrm{R} ; 0.8 \mu \mathrm{g} / \mathrm{ml}$ ) and $6 \%$ HSA in TBS. After thorough washes, the sections were blocked in $2 \%$ HSA in TBS. To localize GluA2, the sections were incubated for $2 \mathrm{~h}$ in a solution containing a 1:40 dilution of $\mathrm{F}\left(\mathrm{ab}^{\prime}\right) 2$ fragment of goat-anti-mouse IgG conjugated to $10 \mathrm{~nm}$ gold particles (Electron Microscopy Sciences), 2\% HSA, and 5 $\mathrm{mg} / \mathrm{ml}$ polyethylene glycol in TBS. After thorough washes with TBS, $\mathrm{PKM} \zeta$ was localized by incubating the sections in a solution consisting of a 1:40 dilution of $\operatorname{IgG~F}\left(\mathrm{ab}^{\prime}\right) 2$ fragment of goat-anti-rabbit conjugated to 
$15 \mathrm{~nm}$ gold particles (Electron Microscopy Sciences), 2\% HSA, and 5 $\mathrm{mg} / \mathrm{ml}$ polyethylene glycol in TBS. Specificities of secondary antibodies were confirmed by an absence of gold particles when the primary antibodies were omitted. After the sections were thoroughly washed and dried, they were counterstained with $1 \%$ uranyl acetate for $45 \mathrm{~min}$.

Quantitative analyses of GluA2 and PKM were taken at $75 \mathrm{kV}$ with a Hitachi H-7000 transmission electron microscope (Hitachi High Technologies America) equipped with an AMT Advantage CCD camera (Advanced Microscopy Techniques). On average, axospinous synapses in the DG outer molecular layer (OML) spanned 3.2 sections and perforated synapses spanned 5.0 sections (Hara et al., 2012). Thus, 15 sets of 5 serial sections were captured at 20,000 $\times$ magnification in the DG OML for each monkey. Images were captured using a systematic random approach and taken only from areas well within the outer two thirds of the molecular layer thickness, where perforant path inputs from the entorhinal cortex terminate (Witter et al., 1989). For each series, the third section was used as a reference section. All dendritic spines containing a postsynaptic density (PSD) on this reference section were marked and followed throughout the series for immunolabeling. At least 120 postsynaptic spines per animal and a total of 2178 spines were identified and included in the analyses. Each dendritic spine was first classified as unlabeled, GluA2 single-labeled, $\mathrm{PKM} \zeta$ single-labeled, or GluA2 and $\mathrm{PKM} \zeta$ double-labeled based on the presence or absence of $10 \mathrm{~nm}$ (GluA2) or $15 \mathrm{~nm}(\mathrm{PKM} \zeta)$ gold particles. A dendritic spine was classified as being labeled when one or more gold particles were present anywhere in the spine or synaptic cleft. This criterion was chosen based on the high specificity of both antibodies and the almost complete lack of gold particles in peptide adsorption control experiments. For labeled spines, the immunogold particles were binned to five postsynaptic compartments using criteria similar to previous studies (He et al., 2000). The synaptic bin included gold particles within the PSD and in the synaptic cleft. The subsynaptic bin consisted of the area directly beneath the PSD but within $60 \mathrm{~nm}$ from the postsynaptic membrane. The perisynaptic bin included labeling on the plasma membrane within $30 \mathrm{~nm}$ from the edges of the PSD and on adjacent sections to the last visible PSD. The plasmalemmal bin included gold particles within $30 \mathrm{~nm}$ from the plasma membrane, but outside of the synaptic and perisynaptic bins. The cytoplasmic bin included all gold particles in the spine head core at least $30 \mathrm{~nm}$ away from the plasma membrane and outside of the synaptic and subsynaptic bins. The PSD length and spine head diameter were measured for each labeled and unlabeled spine and from these measures, the PSD area and spine volume were derived. PSD area was calculated by summing the PSD lengths across all the sections that the PSD spanned (across the 5 serial sections) and multiplying that by the section thickness (90 nm). Estimates of spine volume were derived by calculating the volume of half of a sphere using the maximum spine head diameter as the sphere diameter. While this method is not as accurate as determining the spine volume by reconstructing the full extent and shape of the spine, the mean and frequency distribution of axospinous synapse size, which is tightly correlated with spine size (Harris and Stevens, 1989), is unaltered with aging in the monkey DG (Hara et al., 2012). Thus, this method of obtaining spine volume estimates is not likely to differentially bias cytoplasmic and total density measures across age groups. Perforated synapses were defined by a presence of at least a $25 \mathrm{~nm}$ discontinuity in the PSD in any of the five sections. The PSD length and area for perforated synapses were determined using the combined lengths of PSD segments. To control for possible variability in background labeling across age groups, images of DG granule cell nuclei were taken and the gold particles were counted. No differences in the number of nuclear gold particles were found across age groups $(p>0.7)$. The electron micrographs were adjusted for brightness and sharpness with Adobe Photoshop (version CS5, Adobe Systems).

Statistical analyses. SPSS 11.0 (SPSS) was used for all statistical analyses. Parametric statistics were used to test for potential differences across groups as the behavioral and molecular data were not significantly different from a normal distribution $(p>0.05$, one-sample KolmogorovSmirnov test). One-way and repeated-measures ANOVA were used to determine whether DNMS acquisition (number of trials to criterion) and accuracy (at delay intervals of 15-600 s), respectively, were different

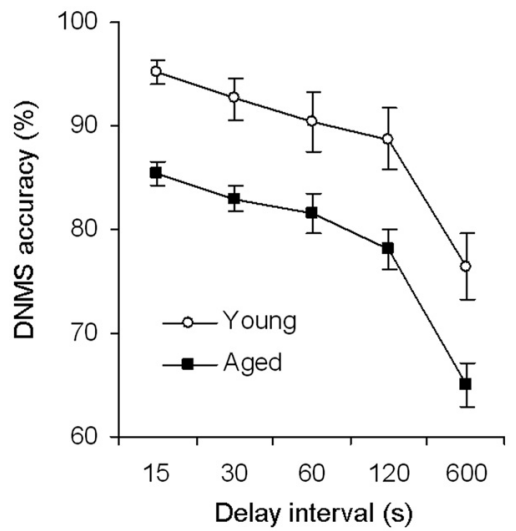

Figure 1. Delay performance on the DNMS test by age groups. Aged monkeys had significantly worse accuracy scores compared with young monkeys across Ionger DNMS delays of $15 \mathrm{~s}$ to $10 \mathrm{~min}$. Group results are expressed as mean \pm SEM. Young, $n=5$; aged, $n=12$.

across age groups. Multivariate ANOVA was used to determine whether neurobiological measures differed by age (young versus aged), molecular profile (unlabeled, single-labeled, and double-labeled), or synaptic morphology (nonperforated versus perforated). Observed power was determined in ANOVA to confirm that the sample size was sufficient to support the data. Because none of the measures were significantly different between the aged premenopausal and peri/postmenopausal groups, the results are collapsed into one aged group. Tukey's post hoc tests probed potential differences between groups while correcting for multiple comparisons. Pearson correlations were used to evaluate the relationships between densities of GluA2 and PKM $\zeta$ in postsynaptic compartments and DNMS measures (acquisition and average accuracy). The correlation analyses were not corrected for multiple comparisons due to the limited sample size of rhesus monkeys and the risk for overcorrection. The number of significant correlations observed between DNMS measures and immunocytochemical data, however, greatly exceeded that predicted by chance and many of the correlations were significant within the aged group. All analyses were two-tailed and the $\alpha$ level was set at 0.05 for statistical significance.

\section{Results}

\section{Behavioral characterization}

DNMS data for most of the monkeys (13 of 17) included in the present study have been described in detail previously (Hara et al., 2012). Aged monkeys ( $n=12$; mean \pm SEM; $734.4 \pm 126.9)$ required significantly more trials than young females $(n=5$; mean \pm SEM; $136.6 \pm 34.3$ ) to acquire the DNMS task with a $10 \mathrm{~s}$ delay (one-way ANOVA; main age effect; $F_{(1,15)}=8.805 ; p=$ 0.010 ; observed power $=0.792)$. When memory demand was increased with longer delay intervals (15-600 s), a repeatedmeasures ANOVA revealed main effects of age and delay, but no age by delay interaction (main age effect, $F_{(1,15)}=16.658, p=$ 0.001 , observed power $=0.968$; delay effect, $F_{(4,60)}=46.375, p=$ $1.04 \times \mathrm{E}^{-17}$, observed power $=1.000$; age by delay interaction, $p=0.941$; Figure 1). Although the age by delay interaction was not significant in this cohort, prior studies and population data from these animals reveal that the memory deficit is strongly dependent on delay such that aged subjects perform comparably to young subjects at short delay intervals but perform significantly worse on longer delays (Rapp and Amaral, 1991; Shamy et al., 2006). In this cohort, no age effect was observed in the acquisition rate for the delayed response task at $0 \mathrm{~s}$, a task that demands no memory components $\left(F_{(1,15)}=0.132 ; p=0.722\right.$; data not shown). Thus, the lower DNMS accuracy scores of the aged monkeys most likely reflect a true memory deficit and not a lack of motivation. 


\section{Expression and subcellular distribution of GluA2 and PKM $\zeta$ in the monkey DG}

The electron microscopic immunolabeling of GluA2 in the monkey DG OML was qualitatively similar to that previously reported in rat hippocampus and monkey cortex (He et al., 2000, 2001). For PKM $\zeta$ localization, an antiserum recognizing the phosphoprotein was chosen, because phosphorylation at the Thr 410 residue reflects increased constitutive kinase activity of PKM $\zeta$ (Kelly et al., 2007; Sacktor, 2011). This antiserum was carefully characterized and shown to specifically recognize $\mathrm{PKM} \zeta$ (see Materials and Methods, Antibodies). PKM $\zeta$ immunolabeling could not be distinguished from $\mathrm{PKC} \zeta$ immunolabeling due to their shared amino acid sequence. However, PKM $\zeta$ is expressed in the forebrain as the major form of $\zeta$ in the near absence of the full-length

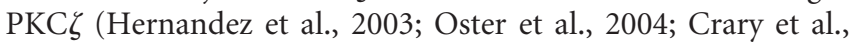
2006). Thus, observed immunoreactivity is presumed to predominantly represent the presence of active PKM $\zeta$.

The majority of OML dendritic spines contained GluA2 $($ mean \pm SEM; young $=68.49 \pm 6.44 \%$; aged $=62.10 \pm 3.27 \%)$ and approximately half were $\mathrm{PKM} \zeta$-positive (young $=57.66 \pm$ $5.12 \%$; aged $=51.71 \pm 2.79 \%)$. Perforated synapses are large synapses that are strongly implicated in memory-related plasticity (Geinisman et al., 1986; Toni et al., 2001; Hara et al., 2012). When perforated synapse spines were examined separately, almost all of them contained GluA2 $(218 / 228=95.6 \%)$ or PKM $\zeta$ $(201 / 228=88.1 \%)$ and a great majority contained both $(192 /$ $228=84.2 \%$ ). We first evaluated whether the incidence of GluA2 or PKM $\zeta$ in OML spines differed between young and aged monkeys. Multivariate ANOVA showed no effect of age on the proportions of unlabeled $(p=0.525)$, GluA2 single-labeled $(p=0.702)$, $\mathrm{PKM} \zeta$ single-labeled $(p=0.419)$, or GluA2 and PKM $\zeta$ doublelabeled spines ( $p=0.298$; Fig. $2 A)$. ANOVA also failed to show a significant age effect when this analysis was confined to perforated synapse spines (unlabeled, $p=0.125$; GluA2 single-labeled, $p=0.452 ; \mathrm{PKM} \zeta$ single-labeled, $p=0.512$; GluA2 and PKM $\zeta$ double-labeled, $p=0.823$; Fig. $2 B$ ).

Spine and synapse size are of significance, because thin spines with small synapses have high motility, plasticity, and turnover rate, and are hypothesized to be important for learning (Kasai et al., 2003; Holtmaat et al., 2005; Dumitriu et al., 2010). In contrast, large mushroom spines contain strong, stable synapses enriched with AMPA receptors and are implicated in memory (Nusser et al., 1998; Kasai et al., 2003). ANOVA revealed significant effects of synaptic morphology and molecular profile on synapse size, as measured by PSD area, but no effect of age (perforated $>$ nonperforated, $F_{(1,2174)}=116.685, p=1.58 \times 10^{-26}$, observed power $=1.000$; molecular profile effect, $F_{(3,2174)}=18.34, p=$ $9.43 \times 10^{-12}$, observed power $=1.000$; age effect, $p=0.723$; Fig. $2 C)$. Tukey's post hoc tests confirmed that GluA2 and PKM $\zeta$ double-labeled spines had significantly larger synapses $(0.0594 \pm$ $\left.0.001 \mu \mathrm{m}^{2}\right)$ than GluA2 single- $\left(0.0377 \pm 0.001 \mu \mathrm{m}^{2} ; p=7.0 \times\right.$ $\left.10^{-13}\right), \mathrm{PKM} \zeta$ single- $\left(0.0350 \pm 0.001 \mu \mathrm{m}^{2} ; p=7.0 \times 10^{-13}\right)$, and unlabeled spines $\left(0.0252 \pm 0.0006 \mu \mathrm{m}^{2} ; p=7.0 \times 10^{-13}\right)$. Tukey's post hoc test also showed that unlabeled spines had significantly smaller synapses than GluA2 single- $\left(p=7.0 \times 10^{-13}\right)$, PKM $\zeta$ single- $\left(p=6.46 \times 10^{-10}\right)$, and GluA2 and PKM $\zeta$ doublelabeled spines $\left(p=7.0 \times 10^{-13}\right)$.

To examine the subcellular distribution of GluA2 and PKM $\zeta$, each immunogold particle was assigned to one of five postsynaptic bins on the basis of its localization: synaptic (including the PSD and synaptic cleft), subsynaptic, perisynaptic, plasmalemmal, and cytoplasmic (Fig. $3 A-C$ ). In both young and aged monkeys, GluA2 immunogold particles were most abundant in the
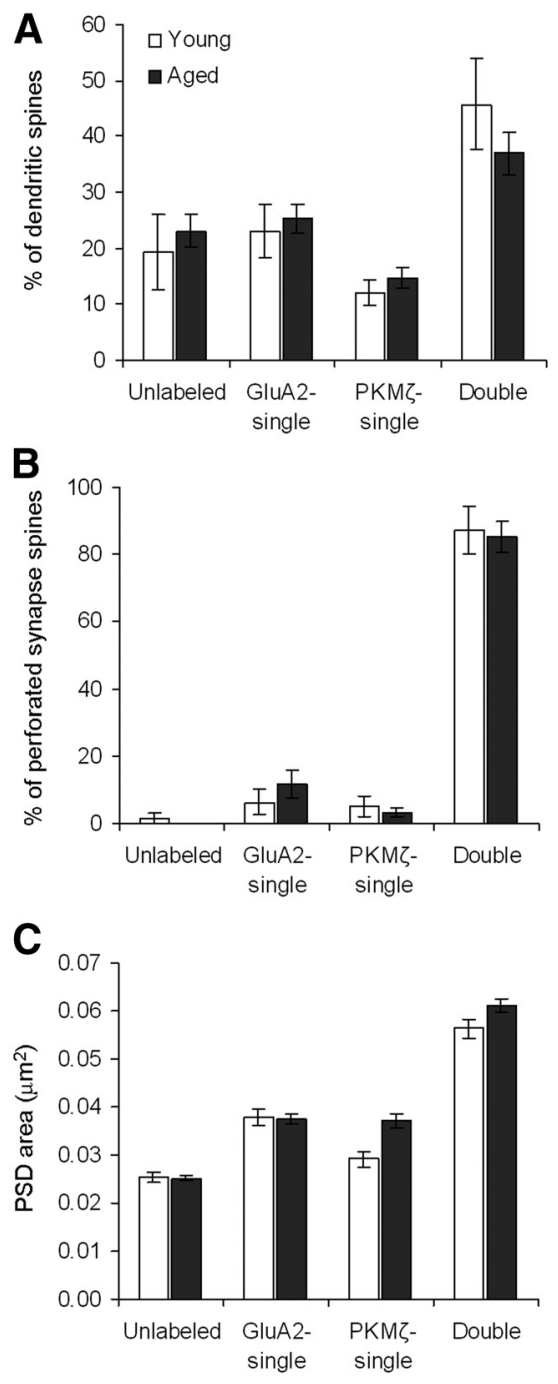

Figure 2. The molecular profiles of monkey DG OML dendritic spines by age groups. $\boldsymbol{A}$, The percentages of dendritic spines that were unlabeled, GluA2 single-labeled, PKM $\zeta$ singlelabeled, and GluA2 and PKM $\zeta$ double-labeled are plotted by age group. $\boldsymbol{B}$, The vast majority of perforated synapse spines contained both GluA2 and PKM $\zeta$, regardless of age. $C$, Independent of age, double-labeled spines had significantly larger synapses, as measured by PSD area, than unlabeled and single-labeled spines. Group results are expressed as mean \pm SEM. Young, $n=$ 5 ; aged, $n=12$.

spine head cytoplasm, presumably reflecting a reserve pool of AMPA receptors or those that have been internalized for recycling or degradation (Fig. 3D). GluA2 immunogold particles were also enriched in the synaptic bin, positioned to contribute to the formation of functional AMPA receptors (Fig. 3D). PKM $\zeta$ immunogold particles were present predominantly in the synaptic bin (Fig. 3E), consistent with its role in regulating the distribution of synaptic proteins such as PSD-95 and GluA2 (Migues et al., 2010; Shao et al., 2011).

\section{Age-related differences in GluA2 labeling in spines coexpressing PKM $\zeta$}

We next determined whether the subcellular distribution of GluA2 and PKM $\zeta$ is altered with aging. Because the number of gold particles in a postsynaptic bin was confounded with synaptic and spine size, the densities of gold particles within each bin and their total were calculated as a function of PSD area and estimated spine volume. Multivariate ANOVA showed a significant main 
A Young
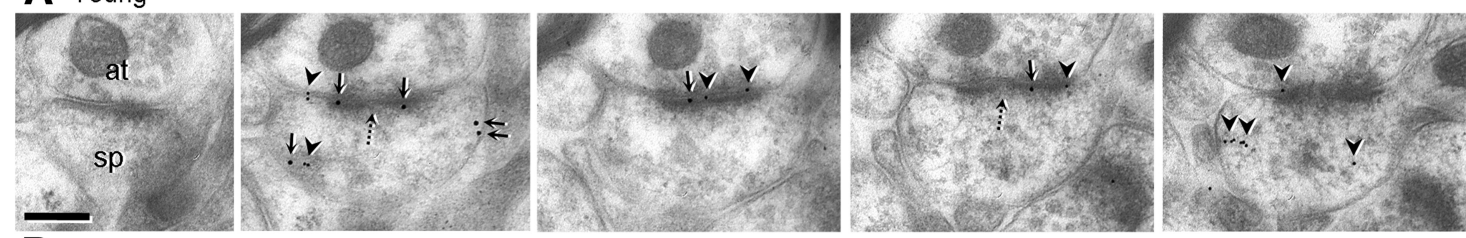

B Aged

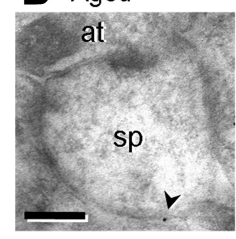

C

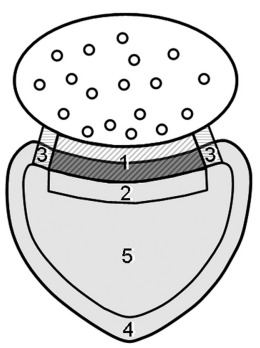

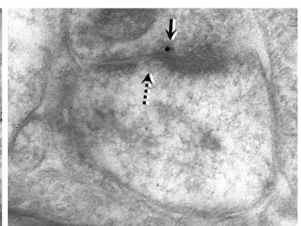

D。
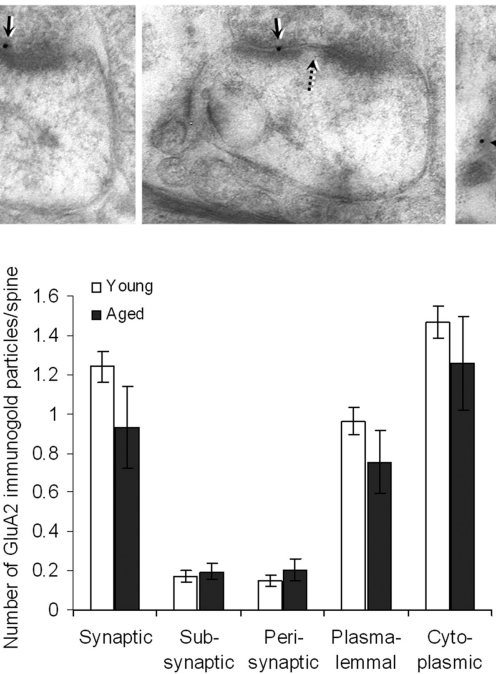

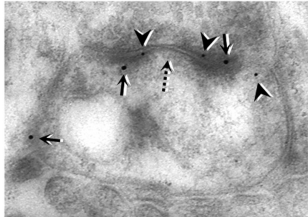

$\mathbf{E}$

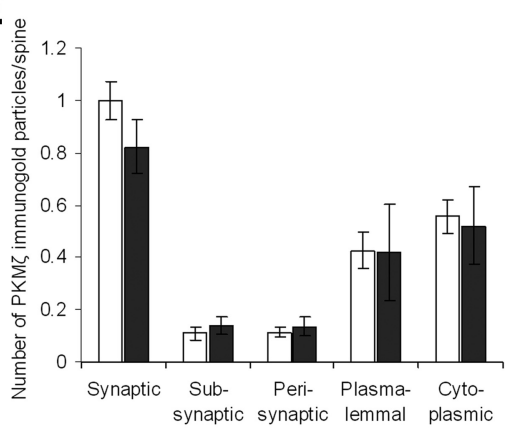

Figure 3. GluA 2 and PKM $\zeta$ immunogold distributions in dendritic spines of young and aged monkey DG OML. $A, B$, Electron micrographs of 5 serial sections display double-labeled perforated synapse spines in young $(\boldsymbol{A})$ and aged $(\boldsymbol{B})$ monkeys. The 10 and $15 \mathrm{~nm}$ gold particles represent GluA2 (arrowheads) and PKM $\zeta$ labeling (arrows), respectively. Dashed arrows point to perforations in the PSD; at, axon terminal; $5 p$, dendritic spine. Scale bars, $200 \mathrm{~nm}$. C, A schematic diagram demonstrates the five postsynaptic bins used to categorize the localization of each gold particle: synaptic (includes the PSD and synaptic cleft; 1), subsynaptic (2), perisynaptic (3), plasmalemmal (4), and cytoplasmic (5). D, E, The average number ( \pm SEM) of GluA2 (D) and PKM $\zeta$ (E) immunogold particles in each postsynaptic bin per labeled dendritic spine are plotted by age. Young, $n=5$; aged, $n=12$.

effect of age on the density of synaptic GluA2 immunogold particles (per $0.1 \mu \mathrm{m}^{2}$ of PSD area) in double-labeled spines but not in singlelabeled spines (double-labeled, $F_{(1,15)}=4.865, p=0.043$, observed power $=0.541$; single-labeled, $p=0.306$; Fig. $4 A$ ). The densities of GluA2 immunogold in other postsynaptic bins were not significantly different across age groups (multivariate ANOVA; $p>0.05$ ). However, ANOVA revealed significant main effects of age on the density of total GluA2 gold particles in both single- and doublelabeled spines (single-labeled, $F_{(1,15)}=16.806, p=0.001$, observed power $=0.969$; double-labeled, $F_{(1,15)}=7.267, p=0.017$, observed power $=0.712$; Figure $4 B$ ). In single- and double-labeled spines, $\mathrm{PKM} \zeta$ densities within each postsynaptic bin, and the total density per spine were not significantly different across age groups (multivariate ANOVA; $p>0.05$ ). In double-labeled spines, however, the average density of PKM $\zeta$ in the synaptic bin (per $0.1 \mu \mathrm{m}^{2}$ of PSD area) correlated with that of GluA2 (Pearson correlation; $n=17 ; r=$ 0.490; $p=0.046$; Fig. 4C), consistent with PKM $\zeta$ 's involvement in promoting delivery of GluA2-containing AMPA receptors to synaptic sites (Yao et al., 2008; Migues et al., 2010). Also in double-labeled spines, the average density of total PKM $\zeta$ immunogold particles (per $0.1 \mu \mathrm{m}^{3}$ of dendritic spine volume) correlated with that of GluA2 (Pearson correlation; $n=17 ; r=0.707 ; p=0.001$; Fig. $4 D$ ).

\section{Relationships between GluA2 and PKM $\zeta$ expression and cognitive function}

Bivariate correlation analysis evaluated potential relationships between recognition memory in young and aged monkeys and DG GluA2 and PKM $\zeta$ expression. Due to the limited sample size of rhesus monkeys and the risk for overcorrection, the analysis was not corrected for multiple comparisons. However, the num-
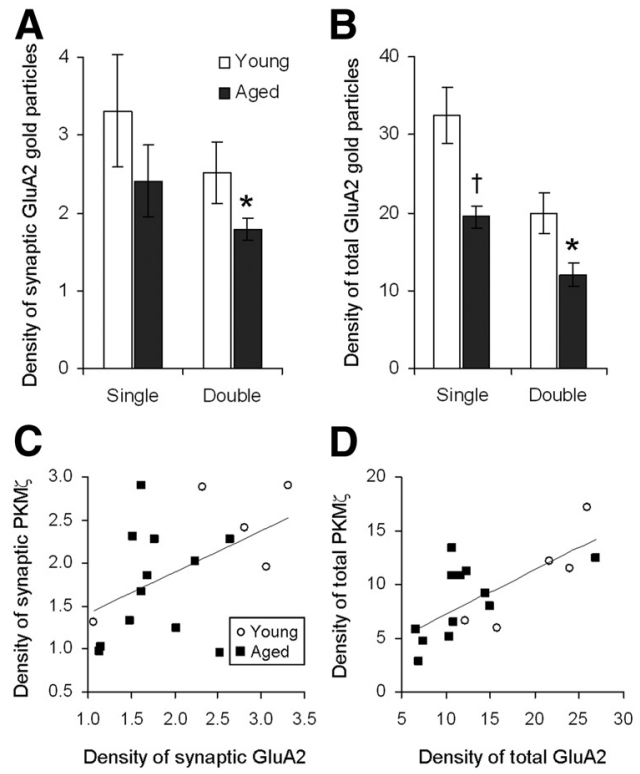

Figure 4. Densities of synaptic and total GluA2 immunogold particles in DG OML dendritic spines by age and in relation to PKM $\zeta$. $A$, The density of synaptic GluA2 immunogold particles (per $0.1 \mu \mathrm{m}^{2}$ of PSD area) was lower in aged compared with young monkeys in double-labeled, but not single-labeled spines. ${ }^{*} p<0.05$. $\boldsymbol{B}$, The densities of total GluA2 immunogold particles (per $0.1 \mu \mathrm{m}^{3}$ of dendritic spine volume) in single- and double-labeled spines were significantly lower in aged compared with young monkeys. Group results are expressed as mean \pm SEM; ${ }^{*} p<0.05,+p<0.01$. C, In dendritic spines coexpressing GluA2 and PKM $\zeta$, the average density of synaptic GluA2 (per $0.1 \mu \mathrm{m}^{2}$ of PSD area) correlated with that of PKM $\zeta$. $D$, In double-labeled spines, the average density of total GluA2 (per $0.1 \mu \mathrm{m}^{3}$ of dendritic spine volume) correlated with that of PKM $\zeta$. Young, $n=5$; aged, $n=12$. 

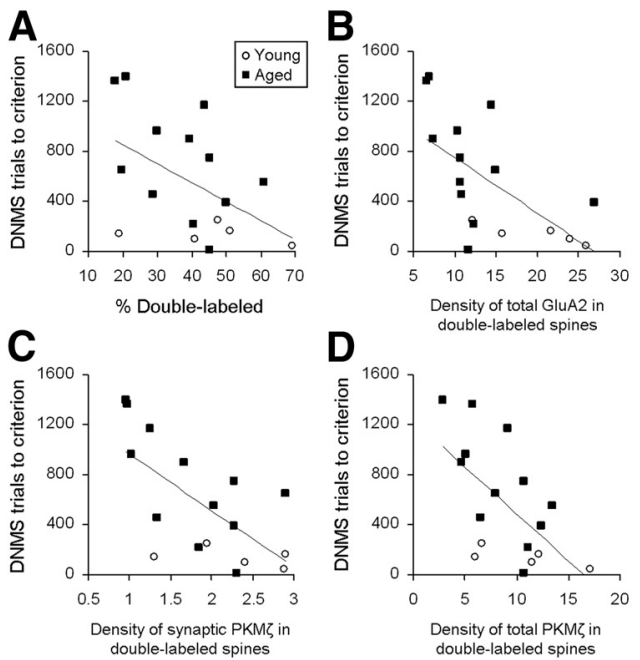

Figure 5. GluA2 and PKM $\zeta$ immunolabeling in the DG OML for individual subjects in relation to DNMS acquisition. DNMS acquisition (number of trials to criterion) inversely correlated with the percentage of dendritic spines double-labeled with $\operatorname{GluA2}$ and $\operatorname{PKM} \zeta(\boldsymbol{A})$. In double-labeled spines, densities of total GluA2 (per $0.1 \mu \mathrm{m}^{3}$ of dendritic spine volume; $\boldsymbol{B}$ ), synaptic PKM $\zeta$ (per $0.1 \mu \mathrm{m}^{2}$ of PSD area; $\boldsymbol{C}$ ), and total PKM $\zeta$ (per $0.1 \mu \mathrm{m}^{3}$ of dendritic spine volume; $\boldsymbol{D}$ ) inversely correlated with DNMS acquisition. $n=17$.

ber of significant correlations observed (15) significantly exceeded that predicted by chance (2.6).

We first examined the relationship between DNMS acquisition (the number of trials to reach the criterion of $90 \%$ accuracy with a $10 \mathrm{~s}$ delay) and the expression of GluA2 and PKM $\zeta$. A significant inverse correlation emerged between acquisition and the percentage of GluA2 and PKM $\zeta$ double-labeled spines, such that monkeys with more double-labeled spines learned the task faster (Pearson correlation; $n=17 ; r=-0.492 ; p=0.045$; Fig. $5 A$ ). In double-labeled spines, the densities of cytoplasmic (per $0.1 \mu \mathrm{m}^{3}$ of dendritic spine volume), plasmalemmal (per $0.1 \mu \mathrm{m}^{2}$ of dendritic spine surface area), and total GluA2 immunogold particles (per $0.1 \mu \mathrm{m}^{3}$ of dendritic spine volume; Fig. $5 B$ ) were inversely correlated with DNMS acquisition $(n=17$; cytoplasmic, $r=-0.567, p=0.018$; plasmalemmal, $r=-0.502, p=$ 0.040 ; total, $r=-0.623, p=0.008)$. Similarly, the densities of synaptic (per $0.1 \mu \mathrm{m}^{2}$ of PSD area; Fig. $5 C$ ), cytoplasmic (per 0.1 $\mu \mathrm{m}^{3}$ of dendritic spine volume), and total PKM $\zeta$ immunogold particles (per $0.1 \mu \mathrm{m}^{3}$ of dendritic spine volume; Fig. $5 D$ ) also inversely correlated with task acquisition in double-labeled spines $(n=17$; synaptic, $r=-0.663, p=0.004$; cytoplasmic, $r=$ $-0.502, p=0.040$; total, $r=-0.613, p=0.009$ ). These correlations between $\mathrm{PKM} \zeta$ densities and DNMS acquisition were also significant when the analysis was confined to aged animals (Pearson correlation, $n=12$; synaptic, $r=-0.672, p=0.017$; cytoplasmic, $r=-0.706, p=0.010$; total, $r=-0.682, p=0.015)$, but were not significant in the young group ( $p>0.05$ for all). In contrast to the results in double-labeled spines, the densities of GluA2 and PKM $\zeta$ in postsynaptic bins of single-labeled spines failed to correlate with DNMS acquisition $(p>0.05)$.

We next examined possible relationships between GluA2 and $\mathrm{PKM} \zeta$ distributions and the integrity of recognition memory, measured as DNMS delay accuracy averaged across increasing retention intervals (15-600 s). Pearson correlation revealed that memory scores for DNMS inversely correlated with the percentage of unlabeled spines (Fig. 6A) and positively correlated with the percentage of double-labeled spines (Fig. $6 B ; n=17$; unlabeled, $r=-0.505, p=0.039$; double-labeled, $r=0.545, p=$
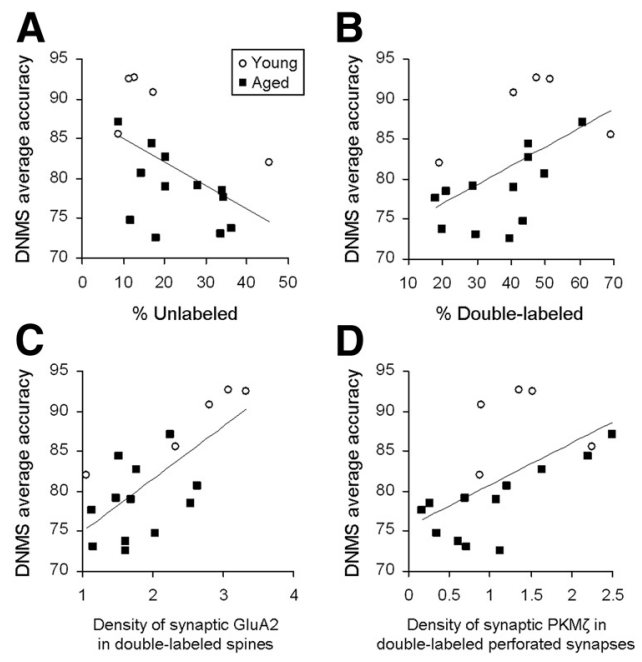

Figure 6. GluA2 and PKM $\zeta$ immunolabeling in the DG OML for individual subjects in relation to DNMS delay performance. DNMS accuracy (average across all delay intervals) inversely correlated with the percentage of unlabeled spines $(\boldsymbol{A})$, and positively correlated with the percentage of double-labeled spines $(\boldsymbol{B})$, the density of synaptic GluA2 (per $0.1 \mu \mathrm{m}^{2}$ of PSD area) in double-labeled spines $(\boldsymbol{C})$, and the density of synaptic PKM $\zeta$ (per $0.1 \mu \mathrm{m}^{2}$ of PSD area) in double-labeled perforated synapse spines $(\boldsymbol{D}) . n=17$.

$0.024)$. The latter correlation was also significant among the aged monkeys considered separately $(n=12 ; r=0.606, p=0.037)$, but was not significant in the young group $(p>0.05)$. This suggests a direct relationship between the synaptic representation of these key plasticity molecules and the effects of aging on hippocampal memory. In double-labeled spines, the density of synaptic GluA2 immunogold particles (per $0.1 \mu \mathrm{m}^{2}$ of PSD area) correlated with DNMS delay performance $(n=17 ; r=0.702 ; p=$ 0.002 ; Fig. $6 C$ ), and this correlation was significant in both nonperforated $(n=17 ; r=0.629 ; p=0.007)$ and perforated synapses ( $n=17 ; r=0.636 ; p=0.006)$. Additionally, the density of cytoplasmic GluA2 (per $0.1 \mu \mathrm{m}^{3}$ of dendritic spine volume) in double-labeled spines positively correlated with DNMS accuracy $(n=17 ; r=0.496 ; p=0.043)$. Also in double-labeled spines, the densities of synaptic (per $0.1 \mu \mathrm{m}^{2}$ of PSD area) and total (per 0.1 $\mu \mathrm{m}^{3}$ of dendritic spine volume) $\mathrm{PKM} \zeta$ immunogold particles positively correlated with recognition accuracy $(n=17$; synaptic, $r=0.509, p=0.037$; total, $r=0.514, p=0.035)$. Notably, the correlation between synaptic $\mathrm{PKM} \zeta$ and memory performance was driven predominantly by perforated synapses $(n=17 ; r=0.558$; $p=0.020$; Fig. $6 D)$ as the correlation failed to reach significance in nonperforated synapses (synaptic PKM $\zeta$ in nonperforated synapses; $p=0.059)$. This correlation in double-labeled perforated synapses was also significant among the aged group $(n=12 ; r=0.759 ; p=$ $0.004)$, but not among the young group $(p>0.05)$.

In single-labeled spines, the densities (per $0.1 \mu \mathrm{m}^{3}$ of dendritic spine volume) of total GluA2 and total $\mathrm{PKM} \zeta$ positively correlated with DNMS average accuracy $(n=17$; total GluA2, $r=0.648 ; p=0.005$; total PKM $\zeta, r=0.659 ; p=0.004)$. No correlations were found between DNMS accuracy and the densities of GluA2 or PKM $\zeta$ in any of the postsynaptic bins of singlelabeled spines $(p>0.05)$.

\section{Discussion}

The present report provides the first demonstration of synaptic molecular correlates of aging and recognition memory decline in a nonhuman primate model (summarized in Fig. 7). Our results highlight postsynaptic spines expressing both GluA2 and PKM $\zeta$ 

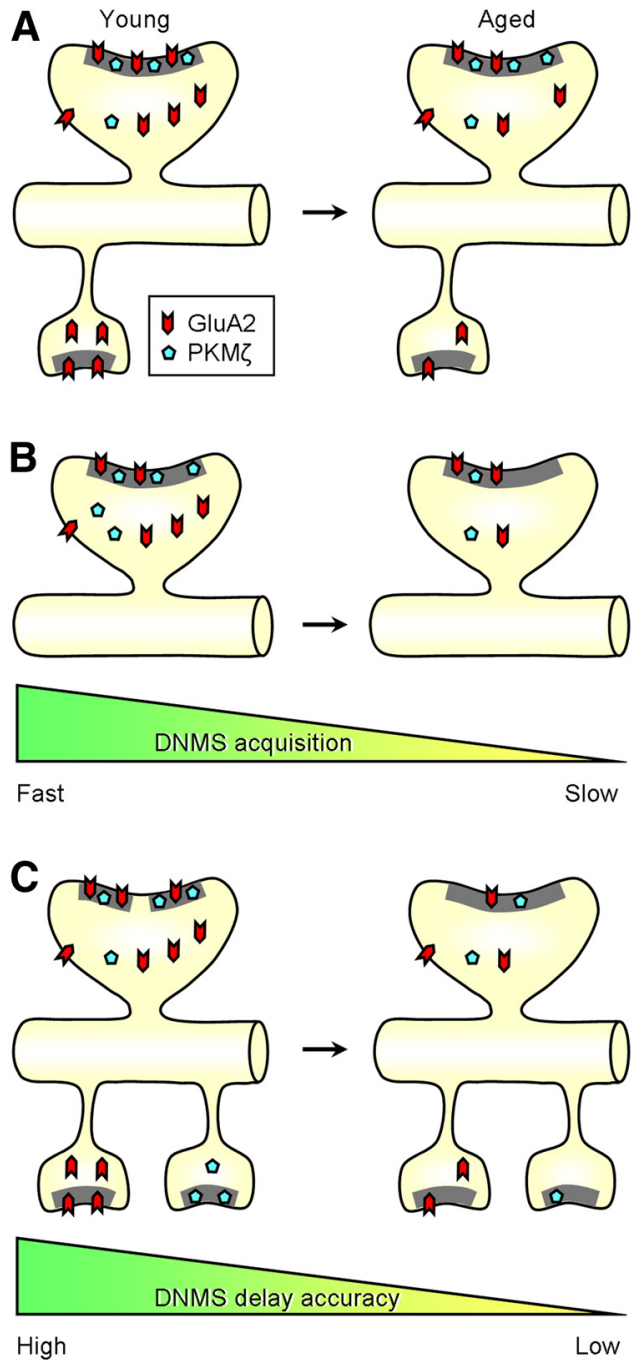

Figure 7. Schematic diagrams illustrating GluA2 and PKM $\zeta$ distributions and densities in relation to aging, learning, and memory. GluA2 and PKM $\zeta$ double-labeled spines (shown above the dendrite) had larger PSDs (gray line) than GluA2 single- and PKM $\zeta$ single-labeled spines (shown below the dendrite), regardless of age. $A$, Compared with young adults, aged monkeys had decreased densities of synaptic GluA2 in double-labeled spines. Aged monkeys also had a lower density of total GluA2 in double- and single-labeled spines. $\boldsymbol{B}$, Fast DNMS task acquisition was associated with high densities of cytoplasmic, plasmalemmal, and total GluA2; and high densities of synaptic, cytoplasmic, and total PKM $\zeta$ in double-labeled spines. C, DNMS delay accuracy was positively associated with densities of synaptic GluA2 and PKM $\zeta$ in double-labeled perforated synapse (broken gray line) spines. Densities of cytoplasmic GluA2 and total PKM $\zeta$ in double-labeled spines also correlated with DNMS accuracy. In single-labeled spines, densities of total GluA2 and total PKM $\zeta$ correlated with DNMS accuracy.

as a class of spines that may be important in memory. Within this population of double-labeled spines, we found an age-related decrease in synaptic GluA2 that correlated with recognition memory scores. Furthermore, synaptic expression of $\mathrm{PKM} \zeta$ in double-labeled spines was coupled with both task acquisition and DNMS delay performance. Together, our findings shed light on key synaptic variables in the primate hippocampus that appear positioned to regulate the cognitive outcome of aging.

Rhesus monkeys are vulnerable to age-related hippocampal dysfunction and recognition memory deficits in a manner similar to humans (Presty et al., 1987; Moss et al., 1988; Rapp and Amaral, 1991); however, some aged monkeys are relatively resistant to memory decline and exhibit cognitive abilities similar to those of young adults (Rapp and Amaral, 1991). Because rhesus monkeys do not develop Alzheimer's disease (Gearing et al., 1996; Sloane et al., 1997; Peters et al., 1999; Kimura et al., 2003), the effects of aging can be examined without the confounding factors inherent to neurodegenerative disorders. Thus, this nonhuman primate model has proved useful for exploring neurobiological parameters that are coupled to individual differences in age-related cognitive decline (Dumitriu et al., 2010; Hara et al., 2011a, 2012). In this study, the DG was targeted because the perforant path input to the DG is a well defined projection that is altered with aging (Flood et al., 1987; Cabalka et al., 1992; Morrison and Hof, 1997; Yassa et al., 2010), and energy metabolism in the DG correlates with recognition memory (Small et al., 2004). In the absence of agerelated changes in synaptic density or size in the monkey DG (Hara et al., 2012), we examined the synaptic distributions of two key proteins that are highly implicated in memory: GluA2 and PKM $\zeta$ (Mead and Stephens, 2003; Migues et al., 2010; Sacktor, 2011).

While the distribution of GluA2 has been reported previously (Vissavajjhala et al., 1996; He et al., 2000), this is the first study documenting the precise subcellular locations of $\mathrm{PKC} / \mathrm{M} \zeta$, presumed to be predominantly $\mathrm{PKM} \zeta$ in the monkey hippocampus (Hernandez et al., 2003; Oster et al., 2004; Crary et al., 2006). While many short-acting molecules have been implicated in memory formation (i.e., CaMKII, MAPK, CREB, etc.), $\mathrm{PKM} \zeta$ is unique in its enduring requirement for memory maintenance (Sacktor, 2011), and its effects can persist for months, if not longer (Shema et al., 2009). Similar to many other active forms of kinases such as Akt and LIM kinase (Yildirim et al., 2008, 2011), the phosphorylated form of $\mathrm{PKM} \zeta$ was present predominantly in the PSD. In dendritic spines coexpressing PKM $\zeta$ and GluA2, their densities in the synaptic bin correlated with each other. Together, our findings are consistent with PKM $\zeta$ 's role in promoting synaptic delivery and retention of GluA2-containing AMPA receptors (Yao et al., 2008; Migues et al., 2010) and suggest that PKM $\zeta$ may exert this role at the PSD.

The GluA2 and PKM $\zeta$ double-labeled spines had synapses that were on average $60 \%$ larger than those of GluA2 single- and $\mathrm{PKM} \zeta$ single-labeled spines, and more than twice the size of unlabeled spine synapses, regardless of age. Furthermore, the great majority of perforated synapse spines $(84.2 \%)$ contained both GluA2 and PKM $\zeta$. Perforated synapses are large synapses proposed to be a structural correlate of enhanced synaptic efficacy and are strongly implicated in memory-related plasticity (Geinisman et al., 1986; Toni et al., 2001). The percentage of spines that were double-labeled in the DG OML correlated with the subject's task acquisition and memory performance on the DNMS. Thus, consistent with previous work in the DG (Hara et al., 2012), large mushroom spines with perforated synapses appear to be the class of spines important for recognition memory. Accordingly, DNMS accuracy in individual monkeys inversely correlated with the percentage of unlabeled spines, which were the smallest class of spines. The critical synaptic subtypes coupled with cognitive decline appear to be different across brain regions and dependent on the types of cognitive function (Hara et al., 2011b). For example, our findings in the DG are in striking contrast to a study in area 46 of the dorsolateral prefrontal cortex, which showed that the smallest of the thin spines, characterized by high plasticity and turnover rate (Kasai et al., 2003; Holtmaat et al., 2005), were associated with task learning and were the most vulnerable to aging (Dumitriu et al., 2010).

One of the key age-related differences observed was the decreased density of synaptic GluA2 in double-labeled spines, a measure that correlated with accuracy across increasing delays on DNMS. This finding is compatible with a study in the rat amygdala showing a 
strong correlation between fear memory and GluA2 protein expression in PSD fractions (Migues et al., 2010). While the decrease in synaptic GluA2 maybe a consequence, instead of a cause, of memory decline, this possibility is unlikely as memory loss can be prevented by blocking GluA2 endocytosis (Migues et al., 2010).

Aged monkeys also exhibited a lower overall density of GluA2 in dendritic spines, even though the spine size and morphology were equivalent to young. A previous confocal microscopic study found no effect of age on gross GluA2/3 protein levels in the monkey DG OML (Gazzaley et al., 1996). The electron microscopic methods used in this current study, however, extend this work by providing subunit specificity and subcellular resolution as well as morphological and molecular characteristics of individual axospinous synapses. Compared with aged monkeys, young adults had more GluA2 not only within the synapse but also in the reserve pool, suggesting greater GluA2-containing AMPA receptor availability for mobilization and insertion into the synapse upon stimulation. Young monkeys may simply have more GluA2 mRNA in the DG than aged subjects, similar to findings in rat models of aging (Pagliusi et al., 1994). Alternatively, GluA2containing AMPA receptors in young animals may be more effectively recycled than in aged animals and/or degraded at a lower rate by lysosomes; both of these possibilities would result in a higher total level of GluA2 in the postsynaptic spine. Interaction of $N$-ethylmaleimide-sensitive fusion protein (NSF) with GluA2 disrupts the interaction of GluA2 with proteins that are critical for receptor internalization, such as PICK1 and AP2 (Man et al., 2000; Hanley et al., 2002), and may prevent internalization and lysosomal degradation of AMPA receptors (Noel et al., 1999; Lee et al., 2004). PKM $\zeta$ may act through the NSF/GluA2 interaction to prevent the removal of AMPA receptors from synaptic sites and to maintain constitutive recycling of receptors (Yao et al., 2008; Migues et al., 2010). In accordance with this possibility, the densities of synaptic and total PKM $\zeta$ in double-labeled spines correlated with those of GluA2.

The correlations observed between PKM $\zeta$ levels and cognitive performance are particularly intriguing. While the densities of $\mathrm{PKM} \zeta$ immunogold particles in individual bins failed to differ reliably across age groups, synaptic, cytoplasmic, and total densities of $\mathrm{PKM} \zeta$ in double-labeled spines significantly correlated with DNMS task acquisition such that monkeys with higher $\mathrm{PKM} \zeta$ densities learned the task faster. PKM $\zeta$ abundance in the spine synapse and cytoplasm likely increases the capacity and speed of incorporating GluA2-containing AMPA receptors into the synapse (Yao et al., 2008; Migues et al., 2010) and, in turn, may enhance the rate at which the monkeys acquire the DNMS nonmatching rule. Consistent with this interpretation, in double-labeled spines, densities of plasmalemmal, cytoplasmic, and total GluA2, all of which likely reflect the reserve pool or those in transit to and from the synapse, also correlated with DNMS acquisition.

$\mathrm{PKM} \zeta$ levels were also coupled with recognition memory, in agreement with studies demonstrating a significant role of $\mathrm{PKM} \zeta$ in memory storage (Pastalkova et al., 2006; Sacktor, 2011). In doublelabeled spines, the densities of total and synaptic PKM $\zeta$ immunogold particles correlated with DNMS average accuracy and the latter correlation was driven mainly by perforated synapses. The density of synaptic GluA2 also correlated with DNMS accuracy, although this correlation was not limited to perforated synapses. Our results are in line with previous work in the monkey DG demonstrating that perforated synapse densities correlate with recognition memory (Hara et al., 2011a, 2012). Our data also suggest that in the primate hippocampus, perforated synapses may be one of the key locations in which $\mathrm{PKM} \zeta$ exerts its effect on memory.
In summary, aged monkeys compared with young have a decreased density of synaptic GluA2 in large dendritic spines coexpressing $\mathrm{PKM} \zeta$, and this decrease correlates with impaired recognition memory. Synaptic $\mathrm{PKM} \zeta$ may promote continued delivery of GluA2-containing AMPA receptors to the synapse and protect aged individuals from recognition memory decline. While the causal relationship cannot be definitively resolved from the current study, this interpretation is consistent with a report showing enhancement of long-term memory by PKM $\zeta$ overexpression (Shema et al., 2011). These potential mechanisms of memory preservation in the aging population present an attractive target for treating cognitive decline.

\section{References}

Cabalka LM, Hyman BT, Goodlett CR, Ritchie TC, Van Hoesen GW (1992) Alteration in the pattern of nerve terminal protein immunoreactivity in the perforant pathway in Alzheimer's disease and in rats after entorhinal lesions. Neurobiol Aging 13:283-291.

Calhoun ME, Mao Y, Roberts JA, Rapp PR (2004) Reduction in hippocampal cholinergic innervation is unrelated to recognition memory impairment in aged rhesus monkeys. J Comp Neurol 475:238-246.

Chaudhry FA, Lehre KP, van Lookeren Campagne M, Ottersen OP, Danbolt NC, Storm-Mathisen J (1995) Glutamate transporters in glial plasma membranes: highly differentiated localizations revealed by quantitative ultrastructural immunocytochemistry. Neuron 15:711-720.

Crary JF, Shao CY, Mirra SS, Hernandez AI, Sacktor TC (2006) Atypical protein kinase $\mathrm{C}$ in neurodegenerative disease I: PKMzeta aggregates with limbic neurofibrillary tangles and AMPA receptors in Alzheimer disease. J Neuropathol Exp Neurol 65:319-326.

Dumitriu D, Hao J, Hara Y, Kaufmann J, Janssen WG, Lou W, Rapp PR, Morrison JH (2010) Selective changes in thin spine density and morphology in monkey prefrontal cortex correlate with aging-related cognitive impairment. J Neurosci 30:7507-7515.

Flood DG, Buell SJ, Horwitz GJ, Coleman PD (1987) Dendritic extent in human dentate gyrus granule cells in normal aging and senile dementia. Brain Res 402:205-216.

Gazzaley AH, Siegel SJ, Kordower JH, Mufson EJ, Morrison JH (1996) Circuit-specific alterations of N-methyl-D-aspartate receptor subunit 1 in the dentate gyrus of aged monkeys. Proc Natl Acad Sci U S A 93:3121-3125.

Gearing M, Tigges J, Mori H, Mirra SS (1996) A beta40 is a major form of beta-amyloid in nonhuman primates. Neurobiol Aging 17:903-908.

Geinisman Y, de Toledo-Morrell L, Morrell F (1986) Loss of perforated synapses in the dentate gyrus: morphological substrate of memory deficit in aged rats. Proc Natl Acad Sci U S A 83:3027-3031.

Gilardi KV, Shideler SE, Valverde CR, Roberts JA, Lasley BL (1997) Characterization of the onset of menopause in the rhesus macaque. Biol Reprod 57:335-340.

Groc L, Choquet D (2006) AMPA and NMDA glutamate receptor trafficking: multiple roads for reaching and leaving the synapse. Cell Tissue Res 326:423-438.

Hanley JG, Khatri L, Hanson PI, Ziff EB (2002) NSF ATPase and alpha-/ beta-SNAPs disassemble the AMPA receptor-PICK1 complex. Neuron 34:53-67.

Hara Y, Park CS, Janssen WG, Punsoni M, Rapp PR, Morrison JH (2011a) Synaptic characteristics of dentate gyrus axonal boutons and their relationships with aging, menopause, and memory in female rhesus monkeys. J Neurosci 31:7737-7744

Hara Y, Rapp PR, Morrison JH (2011b) Neuronal and morphological bases of cognitive decline in aged rhesus monkeys. Age (Dordr). Jun 28 [Epub ahead of print] PubMed PMID: 21710198.

Hara Y, Park CS, Janssen WG, Roberts MT, Morrison JH, Rapp PR (2012) Synaptic correlates of memory and menopause in the hippocampal dentate gyrus in rhesus monkeys. Neurobiol Aging 33:421.e417-421.e428.

Hardt O, Migues PV, Hastings M, Wong J, Nader K (2010) PKMzeta maintains 1-day- and 6-day-old long-term object location but not object identity memory in dorsal hippocampus. Hippocampus 20:691-695.

Harris KM, Stevens JK (1989) Dendritic spines of CA 1 pyramidal cells in the rat hippocampus: serial electron microscopy with reference to their biophysical characteristics. J Neurosci 9:2982-2997.

He Y, Janssen WG, Rothstein JD, Morrison JH (2000) Differential synaptic 
localization of the glutamate transporter EAAC1 and glutamate receptor subunit GluR2 in the rat hippocampus. J Comp Neurol 418:255-269.

He Y, Hof PR, Janssen WG, Rothstein JD, Morrison JH (2001) Differential synaptic localization of GluR2 and EAAC1 in the macaque monkey entorhinal cortex: a postembedding immunogold study. Neurosci Lett 311:161-164.

Henley JM, Barker EA, Glebov OO (2011) Routes, destinations and delays: recent advances in AMPA receptor trafficking. Trends Neurosci $34: 258-268$.

Hernandez AI, Blace N, Crary JF, Serrano PA, Leitges M, Libien JM, Weinstein G, Tcherapanov A, Sacktor TC (2003) Protein kinase M zeta synthesis from a brain mRNA encoding an independent protein kinase $\mathrm{C}$ zeta catalytic domain. Implications for the molecular mechanism of memory. J Biol Chem 278:40305-40316.

Holtmaat AJ, Trachtenberg JT, Wilbrecht L, Shepherd GM, Zhang X, Knott GW, Svoboda K (2005) Transient and persistent dendritic spines in the neocortex in vivo. Neuron 45:279-291.

Kasai H, Matsuzaki M, Noguchi J, Yasumatsu N, Nakahara H (2003) Structure-stability-function relationships of dendritic spines. Trends Neurosci 26:360-368.

Kelly MT, Crary JF, Sacktor TC (2007) Regulation of protein kinase Mzeta synthesis by multiple kinases in long-term potentiation. J Neurosci 27:3439-3444.

Kessels HW, Malinow R (2009) Synaptic AMPA receptor plasticity and behavior. Neuron 61:340-350.

Keuker JI, Luiten PG, Fuchs E (2003) Preservation of hippocampal neuron numbers in aged rhesus monkeys. Neurobiol Aging 24:157-165.

Kimura N, Tanemura K, Nakamura S, Takashima A, Ono F, Sakakibara I, Ishii Y, Kyuwa S, Yoshikawa Y (2003) Age-related changes of Alzheimer's disease-associated proteins in cynomolgus monkey brains. Biochem Biophys Res Commun 310:303-311.

Lee SH, Simonetta A, Sheng M (2004) Subunit rules governing the sorting of internalized AMPA receptors in hippocampal neurons. Neuron 43:221-236.

Man HY, Lin JW, Ju WH, Ahmadian G, Liu L, Becker LE, Sheng M, Wang YT (2000) Regulation of AMPA receptor-mediated synaptic transmission by clathrin-dependent receptor internalization. Neuron 25:649-662.

Mead AN, Stephens DN (2003) Involvement of AMPA receptor GluR2 subunits in stimulus-reward learning: evidence from glutamate receptor gria2 knock-out mice. J Neurosci 23:9500-9507.

Migues PV, Hardt O, Wu DC, Gamache K, Sacktor TC, Wang YT, Nader K (2010) PKMzeta maintains memories by regulating GluR2-dependent AMPA receptor trafficking. Nat Neurosci 13:630-634.

Morrison JH, Hof PR (1997) Life and death of neurons in the aging brain. Science 278:412-419.

Moss MB, Rosene DL, Peters A (1988) Effects of aging on visual recognition memory in the rhesus monkey. Neurobiol Aging 9:495-502.

Noel J, Ralph GS, Pickard L, Williams J, Molnar E, Uney JB, Collingridge GL, Henley JM (1999) Surface expression of AMPA receptors in hippocampal neurons is regulated by an NSF-dependent mechanism. Neuron 23:365-376.

Nusser Z, Lujan R, Laube G, Roberts JD, Molnar E, Somogyi P (1998) Cell type and pathway dependence of synaptic AMPA receptor number and variability in the hippocampus. Neuron 21:545-559.

Oster H, Eichele G, Leitges M (2004) Differential expression of atypical PKCs in the adult mouse brain. Brain Res Mol Brain Res 127:79-88.

Pagliusi SR, Gerrard P, Abdallah M, Talabot D, Catsicas S (1994) Age-related changes in expression of AMPA-selective glutamate receptor subunits: is calcium-permeability altered in hippocampal neurons? Neuroscience 61:429-433.

Pastalkova E, Serrano P, Pinkhasova D, Wallace E, Fenton AA, Sacktor TC (2006) Storage of spatial information by the maintenance mechanism of LTP. Science 313:1141-1144.

Peters A, Jones EG, Morrison JH (1999) Cerebral cortex: neurodegenerative and age-related changes in structure and function of cerebral cortex. New York: Springer.

Presty SK, Bachevalier J, Walker LC, Struble RG, Price DL, Mishkin M, Cork LC (1987) Age differences in recognition memory of the rhesus monkey (Macaca mulatta). Neurobiol Aging 8:435-440.

Rapp PR, Amaral DG (1991) Recognition memory deficits in a subpopulation of aged monkeys resemble the effects of medial temporal lobe damage. Neurobiol Aging 12:481-486.

Rapp PR, Morrison JH, Roberts JA (2003) Cyclic estrogen replacement im- proves cognitive function in aged ovariectomized rhesus monkeys. J Neurosci 23:5708-5714.

Sacktor TC (2011) How does PKMzeta maintain long-term memory? Nat Rev Neurosci 12:9-15.

Sacktor TC, Osten P, Valsamis H, Jiang X, Naik MU, Sublette E (1993) Persistent activation of the zeta isoform of protein kinase $\mathrm{C}$ in the maintenance of long-term potentiation. Proc Natl Acad Sci U S A 90:8342-8346.

Serrano P, Friedman EL, Kenney J, Taubenfeld SM, Zimmerman JM, Hanna J, Alberini C, Kelley AE, Maren S, Rudy JW, Yin JC, Sacktor TC, Fenton AA (2008) PKMzeta maintains spatial, instrumental, and classically conditioned long-term memories. PLoS Biol 6:2698-2706.

Shamy JL, Buonocore MH, Makaron LM, Amaral DG, Barnes CA, Rapp PR (2006) Hippocampal volume is preserved and fails to predict recognition memory impairment in aged rhesus monkeys (Macaca mulatta). Neurobiol Aging 27:1405-1415.

Shao CY, Sondhi R, van de Nes PS, Sacktor TC (2011) PKMzeta is necessary and sufficient for synaptic clustering of PSD-95. Hippocampus. Advance online publication. Retrieved March 6, 2012. doi: 2010.1002/hipo.20996.

Shema R, Hazvi S, Sacktor TC, Dudai Y (2009) Boundary conditions for the maintenance of memory by PKMzeta in neocortex. Learn Mem $16: 122-128$.

Shema R, Haramati S, Ron S, Hazvi S, Chen A, Sacktor TC, Dudai Y (2011) Enhancement of consolidated long-term memory by overexpression of protein kinase Mzeta in the neocortex. Science 331:1207-1210.

Sloane JA, Pietropaolo MF, Rosene DL, Moss MB, Peters A, Kemper T, Abraham CR (1997) Lack of correlation between plaque burden and cognition in the aged monkey. Acta Neuropathol 94:471-478.

Small SA, Chawla MK, Buonocore M, Rapp PR, Barnes CA (2004) Imaging correlates of brain function in monkeys and rats isolates a hippocampal subregion differentially vulnerable to aging. Proc Natl Acad Sci U S A 101:7181-7186

Tanabe K, Kani S, Shimizu T, Bae YK, Abe T, Hibi M (2010) Atypical protein kinase $\mathrm{C}$ regulates primary dendrite specification of cerebellar Purkinje cells by localizing Golgi apparatus. J Neurosci 30:16983-16992.

Tigges J, Gordon TP, McClure HM, Hall EC, Peters A (1988) Survival rate and life span of rhesus monkeys at the Yerkes regional primate research center. Am J Primatol 15:263-273.

Tisdale EJ (2002) Glyceraldehyde-3-phosphate dehydrogenase is phosphorylated by protein kinase Ciota /lambda and plays a role in microtubule dynamics in the early secretory pathway. J Biol Chem 277:3334-3341.

Toni N, Buchs PA, Nikonenko I, Povilaitite P, Parisi L, Muller D (2001) Remodeling of synaptic membranes after induction of long-term potentiation. J Neurosci 21:6245-6251.

Vissavajjhala P, Janssen WG, Hu Y, Gazzaley AH, Moran T, Hof PR, Morrison $\mathrm{JH}$ (1996) Synaptic distribution of the AMPA-GluR2 subunit and its colocalization with calcium-binding proteins in rat cerebral cortex: an immunohistochemical study using a GluR2-specific monoclonal antibody. Exp Neurol 142:296-312.

Walker ML, Herndon JG (2008) Menopause in nonhuman primates? Biol Reprod 79:398-406.

White WO, Seibenhener ML, Wooten MW (2002) Phosphorylation of tyrosine 256 facilitates nuclear import of atypical protein kinase C. J Cell Biochem 85:42-53.

Witter MP, Van Hoesen GW, Amaral DG (1989) Topographical organization of the entorhinal projection to the dentate gyrus of the monkey. J Neurosci 9:216-228.

Yao Y, Kelly MT, Sajikumar S, Serrano P, Tian D, Bergold PJ, Frey JU, Sacktor TC (2008) PKM zeta maintains late long-term potentiation by N-ethylmaleimide-sensitive factor/GluR2-dependent trafficking of postsynaptic AMPA receptors. J Neurosci 28:7820-7827.

Yassa MA, Muftuler LT, Stark CE (2010) Ultrahigh-resolution microstructural diffusion tensor imaging reveals perforant path degradation in aged humans in vivo. Proc Natl Acad Sci U S A 107:12687-12691.

Yildirim M, Janssen WG, Tabori NE, Adams MM, Yuen GS, Akama KT, McEwen BS, Milner TA, Morrison JH (2008) Estrogen and aging affect synaptic distribution of phosphorylated LIM kinase (pLIMK) in CA1 region of female rat hippocampus. Neuroscience 152:360-370.

Yildirim M, Janssen WG, Lou WY, Akama KT, McEwen BS, Milner TA, Morrison JH (2011) Effects of estrogen and aging on the synaptic distribution of phosphorylated Akt-immunoreactivity in the CA1 region of the female rat hippocampus. Brain Res 1379:98-108. 